\title{
Middle managers' role in quality improvement project implementation, are we all on the same page? - A review of current literature
}

\author{
Karolina Zjadewicz ${ }^{1 *}$ D, Deborah White ${ }^{2}$, Shelley Raffin Bouchal ${ }^{2}$ and Sandra Reilly ${ }^{2}$
}

\begin{abstract}
Background: Middle managers within healthcare hold a unique position between senior leadership and frontline staff, and may hold a pivotal function in the implementation of quality improvement (QI) projects. This review aims to explore what is known about healthcare middle managers' role in implementing QI initiatives, and to determine if consensus around their role exists amongst middle managers and other healthcare stakeholders alike.

Methods: A review of the current literature, limited to the English language was undertaken using the databases CINAHL (ESBSCO), PsychInfo, Cochrane, Medline (OVID) and Google Scholar. Of the 2473 articles the search yielded, data was extracted from 16 articles that met the authors' inclusion criteria.

Results: There is scarcity of empirical literature surrounding healthcare middle managers' role in project implementation, and limited consensus in regards to role descriptors is identified. There is general agreement that middle managers have a role in mediating between strategy and day-to-day activities, acting as the primary supporter of frontline staff, and serving as a knowledge broker. However, disagreements about their role are apparent with discrepant perceptions held by the broader stakeholder group (physicians, frontline staff, and senior level leadership) and amongst middle managers themselves.

Conclusions: A limited understanding exists around the specialized role of middle managers within this context, and could be a contributing barrier to QI project implementation. It is suggested that a lack of role clarity amongst middle managers is evident and may be attributed to various contexts and implementation strategies used in quality improvement (QI).
\end{abstract}

Keywords: Middle managers, Quality improvement, Project implementation, Healthcare quality

\section{Background}

Healthcare middle managers (sometimes known as frontline managers) are defined as the first line of leadership with direct contact and supervision of frontline employees and exercise administrative responsibilities, without a clinical role [1]. Their role in the successful uptake of practice changes through

\footnotetext{
* Correspondence: karolina.zjadewicz@ahs.ca

'Quality Improvement Lead, Department of Critical Care Medicine, University of Calgary, ICU Admin, McCaig Tower, Foothills Medical Center, 3134 Hospital Drive NW, Calgary, AB T2N 2T9, Canada

Full list of author information is available at the end of the article
}

QI (quality improvement) project implementation shouldn't be underestimated. Situated between senior leadership and frontline staff, middle managers are able to influence the behaviour of their staff as a result of organizational structures and their large span of control [1-8]. Middle managers act as either principal facilitators or barriers in the implementation of new initiatives $[4,9]$. Their influence stems from their ability to operationally link senior leadership with frontline staff and facilitate implementation by limiting gaps in information and knowledge amongst these two groups [1]. 
To help healthcare middle managers leverage their influence during implementation, their role must be well defined and understood [1]. In response, there has been a surge of literature exploring their role, including a systematic review aimed at identifying hospital manager's activity, engagement and time spent on quality and safety [10]. However, the research to date has not always distinguished specific leadership responsibilities of middle managers as compared to other levels of leadership. Furthermore, role descriptions of healthcare middle managers in QI is often derived from the perspective or observations of other levels of leadership and/or other stakeholders (i.e. clinical staff, physician co-leads, senior leadership) rather than from the middle manager's perspective [4].

This review aims to identify what is known about healthcare middle managers' role in participating and leading QI project implementation. Additionally, this review sets out to determine how other stakeholders (as compared to middle managers themselves) perceive their role, and ascertain if differences exist.

\section{Methods}

\section{Concepts and methodology}

Role in this context is defined as the tasks, activities, and engagement in QI project implementation [10]. Given the extensive considerations within QI projects, this review focuses only on the implementation process. This is defined as the initial introduction of an initiative to a defined clinical area or department.

\section{Search strategy}

Literature from January 1980 to January 2016 limited to the English language was reviewed. Given the narrow scope and scarcity of empirical evidence, the search included publications that discussed conceptual models but excluded editorials and commentaries. An electronic search was done using the following databases: CINAHL (EBSCO), Google Scholar, PsychInfo, Cochrane and Medline (OVID). Reference lists of included literature were examined and additional articles were found using the functions of GOOGLE including "related literature". After duplicates were removed, the search yielded 2473 articles. A detailed description of the search strategy including keywords (k) and subject headings (SH) used can found in Appendix 1.

\section{Screening}

Articles were screened for eligibility by one reviewer (KZ), illustrated within the Preferred Reporting Items for Systematic Reviews and Meta-Analyses (PRISMA) 2009 Flow Diagram (Appendix 2). The inclusion criteria included (i) description of middle management's role and/or influence on QI implementation, and (ii) description of tasks, responsibilities and expectations of middle management in QI implementation. Middle managers were also referred to as unit managers, frontline managers, patient care managers, nurse managers, and ward managers.

\section{Results}

This section provides an overview of the included articles and their respective key findings using the following headings: description of the studies; middle managers role in QI implementation according to various stakeholders; middle managers' perceptions of their role in QI implementation; and middle managers' description of perceived barriers and facilitators to QI implementation.

\section{Description of the studies}

Of the 16 articles that met inclusion criteria, ten were primary research articles, two were literature reviews, and four were conceptual papers (Table 1). Geographical location and setting of articles are described in Table 1. Only four of the 16 articles distinguished the perspective of middle managers from other levels of leadership.

Table 1 Study characteristics (type of research, country of origin and concepts explored) of the 16 articles that met inclusion criteria

\begin{tabular}{ll}
\hline Characteristic & No (\%) total \\
\hline Type of Article & \\
Primary Research & $9(56.3)$ \\
$\quad$ Qualitative & $7(43.7)$ \\
$\quad$ Mixed Methods & $3(18.8)$ \\
Literature Review & $2(12.5)$ \\
Conceptual & $4(25.0)$ \\
Country of Origin & \\
Australia & \\
Canada & $1(6.25)$ \\
Ireland & $1(6.25)$ \\
Finland & $1(6.25)$ \\
Sweden & $1(6.25)$ \\
United Kingdom & $1(6.25)$ \\
United States & $2(12.5)$ \\
Clinical Setting & $4(25)$ \\
Acute (non-specific) & \\
Primary Care (non-specific) & \\
Mixed Clinical settings & $6(37.5)$ \\
Homecare & $4(25)$ \\
Non-Health Care & $5(31.3)$ \\
Various Stakeholders' Perspective of the & $1(6.25)$ \\
Middle Managers' Role in Ql Implementation & $1(6.25)$ \\
Middle Managers' own perception of their & $8(50.0)$ \\
role in project implementation & $4(25.0)$ \\
Description of the facilitators and barriers & $2(12.5)$ \\
middle managers face in project implementation & \\
\hline
\end{tabular}


Various stakeholders' perspective of the middle managers' role in QI implementation

Although many of the studies $(n=8)$ included middle managers within their sample, the middle manager's perspective was not separated from the broader healthcare team (physicians, upper management, frontline staff) in either the data collection and/or analysis $[1,6-9,11-13]$. Within a combined stakeholder perspective, healthcare middle managers are perceived to have four roles in implementation [14]. These roles include: coordinator, communicator, campaigner and conflict manager.

Middle managers as coordinators are described as linking and coordinating efforts between different levels of the organization. They have a responsibility in leading the multidisciplinary team, advocating for resources $[5,11,12]$ and strengthening the role of frontline workers in QI implementation [12, 15]. As a communicator, middle managers are described as needing to synthesize organizational strategies, translating them into day-to-day activities for the frontline $[6,14,16,17]$ and positioning improvement initiatives in the context of clinical relevance [14, 16]. Similarly, middle managers function much like a two-way conduit, channelling communications from the boardroom to the frontline in a timely efficient manner as well as funnelling frontline concerns and issues to senior leaders [6].

Middle managers are also described as campaigners who champion the project by justifying the need for implementation. They provide clearly outlined objectives and responsibilities to frontline staff $[6,14,16,17,18]$, and ensure its relevance within a clinical context. Middle managers promote programs by prioritizing and translating QI initiatives to align with both organizational and frontline priorities [9]. Lastly, middle managers are conflict managers who mediate potential barriers to project implementation $[6,18]$. This may include clarifying misunderstandings about the initiative, and ensuring feedback forums are in place to gather and review frontline staff's concerns around the project.

\section{Middle managers' own perceptions about their role in QI implementation}

Middle managers' perceptions of their role in QI implementation are presented in Table 2. Within the four studies there is consensus on two role functions; linking staff to certain responsibilities and translating broad strategies into actionable tasks $[1,17,19,20]$. However, not all middle managers provided descriptions around their role in selling and championing innovation to staff, and altering daily operations to meet strategical direction $[17,19]$.
Table 2 Middle managers' perceptions about their role in QI

\begin{tabular}{ll}
\hline Role description & References \\
\hline $\begin{array}{l}\text { Translating broad strategies into actionable tasks } \\
\text { (adapting to frontline operations) }\end{array}$ & {$[1,17,19,20]$} \\
Altering daily operations to meet strategical direction & {$[1,17,19]$} \\
Linking staff with certain responsibilities & {$[1,17,19,20]$} \\
Selling/championing innovation to staff & {$[1,17,19]$} \\
\hline
\end{tabular}

${ }^{a}$ Role descriptions that did not have full consensus amongst middle managers

Middle managers described their key role of translating the broad strategy of a project into every day operational actions. This requires establishing connections and mediating between frontline staff and upper management, and the synthesis and diffusion of information [1, 17, 19, 20]. To do this, middle managers explain that they are knowledge brokers of daily operations and project strategy as they collaborate with senior leadership and frontline staff in the planning phases of implementation $[1,17,19,20]$. They diffuse and synthesize information related to operations including the feasibility of project implementation, impact on current operations and workload. Related activities include; communicating important project information and available support to frontline employees, monitoring employees' response to the information, fielding any questions they might have, and informing upper management about the project's status [1].

Once a project's strategy is translated into operational tasks, middle managers described their role in altering daily operations to meet the strategic direction of the project [1]. Related activities include; ensuring frontline staff have the necessary resources (i.e., education, supplies) to implement the project, and organizing and utilizing appropriate resources (frontline staff, educators, supplies) in an effective manner as it aligns with the project's strategy $[1,17,19,20]$. Within this role, managers identify what local level considerations are required for project implementation, including accommodations or changes to current/established processes [17, 19].

Lastly, middle managers explained that in order to sustain efforts and overcome resistance; they have a role in encouraging employees to implement the new approach $[1,17,19]$. Some activities within this role include selling or convincing employees of the project worthiness, setting project specific related norms $[1,17,19]$, and maintaining a positive attitude toward implementation efforts $[19,20]$. As project champions, middle managers help frontline employees appreciate the rationale behind any changes in practice and help to facilitate adaptability [1, 17]. Some middle managers explicitly disagree about their 
role as a project champion, and instead prefer to take a "hands off" approach in leading the implementation [20]. Additionally, a survey of 62 nurse managers revealed that amongst the highest ranked roles, their role of selling innovation to staff was ranked as least important [1].

\section{Middle managers' perceived facilitators and barriers to Q I implementation}

Facilitators that middle managers reported centered on their own behaviors, specifically demonstrating a keen interest in the project and the importance of monitoring their feelings of discontent towards the project [20] and contextualizing the project for staff. [19] As they campaigned the project, managers monitored staff responsiveness to help prevent disengagement, and this trajectory to implementation was easier when there was personal interest in the project [19].

Middle managers reported a few barriers to QI implementation. Some of the barriers identified included a lack of knowledge regarding organizational priorities, role overload, and discomfort with the concept of implementation irrespective of the value of or evidence supporting the initiative [20]. Furthermore, middle managers reported that justifying the initiative, or sustaining the implementation required considerable effort in encouraging staff.

\section{Agreement on the role of the middle managers in QI implementation}

Middle managers act as a medium for linking groups by mediating and interpreting connections between several levels of management [6, 17]. They channel project strategies from the boardroom to the frontline in a timely efficient manner as well as funnelling operational concerns and issues to senior leaders [6]. Middle managers are the primary supporter of frontline staff during the implementation of a QI initiative. This is demonstrated by middle managers appropriately delegating responsibilities $[12,17,18]$, and supplying the necessary tools and resources for effective implementation $[6-9,20]$. As such, managers support and empower frontline staff in QI implementation [1, 16, 17, 20]. Middle managers must enact a multitude of skill sets to fulfill their role. These skills may include having strong negotiation and conflict resolution skills, and understanding the initiative both strategically and operationally. It also requires middle managers to position the project in such a way that it has clinical relevance in daily operations.
Table 3 Middle managers' role in Ql: perceptions of other stakeholders, not identified by middle managers

\begin{tabular}{ll}
\hline Role descriptor & References \\
\hline $\begin{array}{l}\text { Transcending inter-professional boundaries, } \\
\text { by leading the multi-disciplinary team in } \\
\text { project implementation }\end{array}$ & {$[5,12,15]$} \\
\begin{tabular}{l} 
Monitoring quality indicators \\
\hline
\end{tabular} & {$[5,9,11,15,16,17]$} \\
\hline
\end{tabular}

Not on the same page: discrepant perceptions of middle managers' role in QI implementation

Despite some agreement around their role, discrepancies in perceptions exist between middle managers and various stakeholders and amongst middle managers themselves. This is illustrated in Tables 2, 3, and 4. For example amongst the healthcare team, there is a perception that the middle manager has a role in transcending inter-professional boundaries and providing leadership to improve the knowledge of the multidisciplinary team $[9,12,15]$. Middle managers do not hold the same perception. In contrast, managers describe their role in changing daily operations to align with strategic direction [17, 19].

Discrepancies also exist amongst middle managers' perceptions of their role in this context (Table 2). In two of the studies, middle managers describe their role as champions of the project that is being implemented [1, 17, 19]. However, not all studies came to similar conclusions, with some middle managers explicitly stating that they do not have a role as project champions but rather passive project implementers [20]. Additionally, there isn't broad consensus amongst managers around their role of altering daily operations to meet the strategical direction of the project, with some clearly differentiating it from their role in linking staff with responsibilities [17, 20].

\section{Discussion}

The aim of this review was to explore what is known about healthcare middle managers' role in implementing QI projects and to determine if agreement around role descriptors exists amongst middle managers and the broader healthcare team. The review demonstrates, that coupled with a scarcity of literature, there isn't broad consensus around the healthcare middle managers' role in QI implementation.

Given the lack of agreement, it is important to consider the context or structure of the quality

Table 4 Middle managers' role in Ql: perceptions of middle managers, not held by combined stakeholder perspective

\begin{tabular}{ll}
\hline Role descriptor & References \\
\hline Altering daily operations to meet strategical direction & {$[1,17,19]$} \\
\hline
\end{tabular}


improvement initiative being implemented. More specifically, distinguishing between a project mandated by senior leadership and a grassroots or frontline driven project. With middle managers having a role in "selling" innovation to staff, it is likely that these projects are mandated, requiring the manager to be directive when gaining buy in from frontline staff. It is also perceived that middle managers have a role in monitoring quality indicators and leading the entire multidisciplinary team $[5,9,11,15,16,17]$, activities that necessitate knowledge of improvement methods, team building and effectiveness. These role descriptions support top-down implementation methodologies that are not always echoed by middle managers themselves.

Some middle managers' concur with the role of "selling" innovation to staff $[1,17,19]$, however, not all middle managers agree. Some rate it as the least important priority [1] and others explain that they are not project champions but rather passive implementers [20]. These managers could be referencing to a collaborative model for QI implementation. Within this model, instead of being directive, managers can engage staff using QI methodologies such as smallscale testing using Plan-Act-Do-Study (PDSA) cycles. This approach allows for the opportunity to codesign projects with frontline staff, with managers further supporting implementation by altering daily operations to meet the strategical direction of the project $[1,17,19]$.

Although the roles described by middle managers can be interpreted to support both a top-down "push" implementation and a collaborative push/pull grassroots project, it is noteworthy that consensus on these roles vary. A possible explanation for the similarities and differences in role descriptions could be attributed to various interpretations of QI methodology and the perceived nature of implementation strategies. Middle managers and other healthcare team members who have had similar experiences may have greater agreement with defining the roles and responsibilities of those involved (including middle managers). Given the varying skill and knowledge levels of QI methods, implementation and change management approaches, practice and organizational contexts of QI initiatives, as well as individual characteristics, it is not surprising that perceptions around the middle managers' role vary.

\section{Getting on the same page: the need for consensus and clarity around the middle managers' role in QI implementation}

Health centers strive to adopt current evidence informed practice to ensure the delivery of an appropriate standard of care for each client [2, 15, 19]. Often, these practices are implemented within a quality improvement (QI) project [19]. However, the complexity of QI projects in the acute clinical setting often impedes implementation-with some studies indicating a failure rate nearing $50 \%[2,19]$. To change this dynamic, QI projects require multi-level leadership [3, 11, 19], specifically designed for different roles and responsibilities [4]. To help support the different roles; clarity and agreement on all roles, including that of middle managers, is required.

Despite their influence, middle managers spend less than $3 \%$ of their time on QI activities [21]. A recent systematic review about hospital managers' role indicates that little focus is placed on those activities pertaining to quality management [10]. Middle managers explain that they tend to feel uncomfortable with the concept of implementing evidence-based practice despite recognizing its value $[20,22]$. They also report being disempowered from the lack of perceived support received from their senior leaders [20]. Additionally, competing priorities have been used as an explanation for their low levels of involvement in implementation efforts [20].

Role ambiguity resulting in a sense of powerlessness amongst middle managers may be restricting them to fulfill their influential roles [20]. This may be negatively impacting implementation, with some healthcare providers explaining that managers themselves can act as a barrier to implementation [5, 9]. Finally, without a clear understanding or agreement of the middle managers role, potential barriers they face (inexperience with project implementation and role overload) may not be identified by senior leaders. This may impede the senior leader's ability to identify and allocate appropriate resources, leaving managers feeling unsupported.

Given that leadership is consistently referenced as a key facilitator in QI project implementation [3, 4, 19], both senior leaders and middle managers should have clarity and consensus around their respective roles in this context. To help facilitate this, a clear understanding and agreement regarding project goals and corresponding implementation strategy is required amongst senior and middle management. Additionally, a collaborative approach in planning implementation could help inform senior leaders about potential barriers identified by middle mangers. To help mitigate barriers and further standardize efforts, adopting a framework for implementation might be helpful. This can also help to empower middle managers to identify what skills they require and request senior leadership support when necessary. Examples of such models may 
include the Improvement Way and Knowledge to Action Cycle [23, 24].

\section{Limitations and future research}

This review has several potential limitations, such as exploring the role of middle managers from various backgrounds (including non-healthcare), without accounting for structure and cultural differences. Additionally, the authors of this paper could not stratify the combined stakeholder perspective by discipline and level of organization (i.e. frontline perspectives vs. senior leadership) for further analysis. Lastly, the review does not explore the role functions of middle managers in the other phases of QI projects, such as creation and sustainability, which are equally as important in implementation success.

Findings that preserve the middle manager perspective in healthcare are limited in scope and to an American primary care and Scottish acute care settings (neither well defined). Future research is needed to understand other factors that may influence the role of the manager including; organizational structure and culture surrounding the project, clinical setting, nature of the project, and resources available. Furthermore, a deeper understanding of the facilitators and barriers faced by middle managers during the implementation of a QI project would seem appropriate. This would help to inform the development of strategies to build capacity amongst middle managers and mobilize their influence to help support QI project implementation.

\section{Conclusions}

A limited understanding exists around the specialized role of middle managers within the context of QI project implementation. There is some evidence to support that a lack of role clarity amongst middle managers may be apparent in day-to-day operations and could be a contributing barrier to QI project implementation. To help mediate this ambiguity, consensus around project goals and corresponding implementation structure (including the possible adoption of a potential framework) should be established and agreed upon amongst both middle management and senior leadership. In conclusion, it would appear that there is a need for more exploratory and quantitative measurement around the role of the middle manager in QI project implementation. It is suggested that if middle managers mutually agree upon roles and responsibilities, they could be empowered to use their influence to facilitate implementation [15].

\section{Appendix 1}

Table 5 Search strategy

\begin{tabular}{|c|c|}
\hline $\begin{array}{l}\text { Search Concept A: } \\
\text { Quality Improvement } \\
\text { Implementation }\end{array}$ & $\begin{array}{l}\text { Search Concept B: } \\
\text { Patient Care Managers }\end{array}$ \\
\hline $\begin{array}{ll}\text { Search terms } \\
\text { - } \\
\text { - } & \text { Progality Improvement Implementation (sh) } \\
\text { - } & \text { Innovation implementation (k) } \\
\text { - } & \text { Evidence based practice } \\
\text { implementation }(k) \\
\text { - } & \text { Research utilization }(k) \\
\text { - } & \text { Practice guidelines (sh) }(k) \\
\text { - } & \text { Clinical practice guidelines (k) }\end{array}$ & 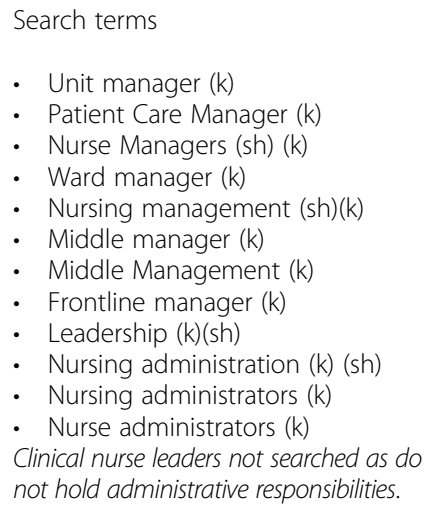 \\
\hline
\end{tabular}

- $\mathrm{K}$ denotes keyword, SH denotes subject heading

- Boolean "or" was used within each of the two search concepts. Final results

were captured by combining the categories using "and"

- Limited to peer reviewed articles in an electronic format, limited to the English language

Inclusion criteria:

(I) Description of middle management's role and/or influence in the organization, specifically in relation to Ql implementation

(II) Description of tasks, responsibilities and expectations of middle management

(III) Relationship between middle management's involvement and QI implementation. Synonyms used to identify middle management in literature (as health regions are organized differently) included nursing leadership, frontline management, ward managers, unit managers, and patient care managers and nursing managers, nurse administrators and were captured with the search terms

(IV) Other synonyms used in the search for "Ql implementation" included program implementation, innovation implementation, evidence based practice implementation, research utilization, and practice guidelines Exclusion criteria:

- Clinical nurse leaders were not identified as being relevant in the search as per definition used in the study's aim (i.e. do not normally administrative responsibilities) Editorials and commentaries 


\section{Appendix 2}

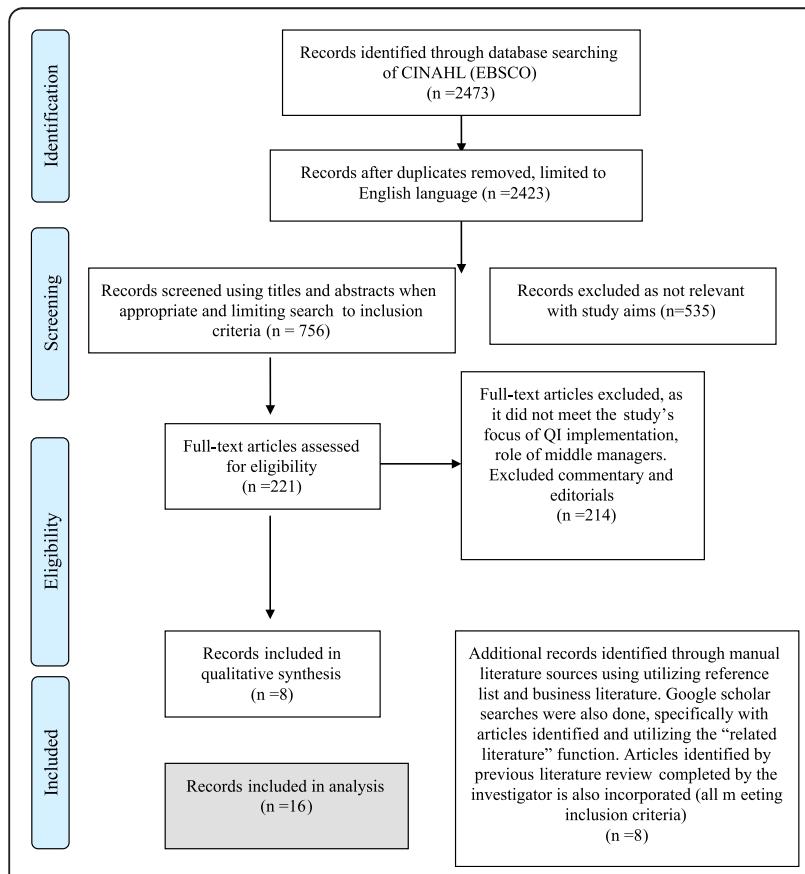

Fig. 1 Prisma 2009 flow diagram. Adapted from www.prisma-statement.org/

\section{Additional file}

Additional file 1: Summary of literature findings: role of middle managers in QI implementation. (DOCX $117 \mathrm{~kb}$ )

\section{Abbreviations}

PRISMA, Preferred Reporting Items for Systematic Reviews and Meta-Analysis; QI, Quality Improvement

\section{Acknowledgements}

N/A.

\section{Funding}

N/A.

\section{Availability of data and materials}

All data generated during and/or analyzed within this review are included in the published manuscript (and its Additional file 1).

\section{Authors' contributions}

The authors all contributed in the writing and review of the manuscript. $K Z$ analyzed and interpreted findings from the literature and constructed the draft of the manuscript. DW: study design and interpretation of the data, SR: intellectual content, SRB: intellectual content. All authors read and approved the manuscript.

\section{Competing interests}

The authors declare that they have no competing interests.

\section{Author details}

'Quality Improvement Lead, Department of Critical Care Medicine, University of Calgary, ICU Admin, McCaig Tower, Foothills Medical Center, 3134 Hospital Drive NW, Calgary, AB T2N 2T9, Canada. ${ }^{2}$ University of Calgary, Faculty of Nursing, Calgary, AB, Canada.
Received: 26 May 2016 Accepted: 11 July 2016

Published online: 04 August 2016

\section{References}

1. Birken S, McClelland, DiMartino L, Kirk M, Lee S, Albert N. Elaborating on theory with middle managers' experience implementing healthcare innocations in practice. Implement Sci. 2016;11(2):1-5.

2. Price M, Fitzgerald L, Kinsman L. Quality improvement: the divergent views of managers and clinicians. J NursManag. 2007;15(1):43-50.

3. Pearson M, Wu S, Schaefer J, Bonomi A, Shortell S, Mendel P, et al. Assessing the implementation of the chronic care model in quality improvement collaboratives. Health ServRes. 2005;40(4):978-96

4. Øvretveit J. The Leaders' Role in Quality and Safety Improvement; A review of Re-search and Guidance; The Improvement Action Evaluation Project. Stockholm: Association of County Councils (Lanstingsforbundet); 2004.

5. Gifford W, Davies B, Edwards N, Griffin P, Lybanon V. Managerial leadership for nurses' use of research evidence: an integrative review of the literature. Worldviews Evid-Based Nurs. 2007;4(3):126-45.

6. Birken $S$, Lee $S$, Weiner B. Uncovering middle managers' role in healthcare innovation implementation. ImplementSci. 2012;7(1):28.

7. Squires M, Tourangeau A, Laschinger HK, Doran D. The link between leadership and safety outcomes in hospitals. J NursManag. 2010;18(8):914-25.

8. Yang J, Zhang Z, Tsui A. Middle manager leadership and frontline employee performance: Bypass, cascading, and moderating effects. J Manag Stud. 2010;47(4):654-78

9. Kirchner J, Parker L, Bonner L, Fickel J, Yano E, Ritchie M. Roles of managers, frontline staff and local champions, in implementing quality improvement: stakeholders' perspectives. J EvalClin Pract. 2012;18(1):63-9.

10. Parand A, Dopson S, Renz A, Vincent C. The role of hospital managers in quality and patient safety: a systematic review. BMJ Open. 2014;4(9): e005055,2014-005055.

11. Gifford W, Davies B, Edwards N, Graham I. Leadership strategies to influence the use of clinical practice guidelines. NursLeadersh (Tor Ont). 2006;19(4):72-88.

12. Kitson A, Silverston $H$, Wiechula R, Zeitz K, Marcoionni D, Page T. Clinical nursing leaders', team members' and service managers' experiences of implementing evidence at a local level. J Nurs Manag. 2011;19(4):542-55.

13. Bahtsevani C, Willman A, Stoltz P, Östman M. Experiences of the implementation of clinical practice guidelines-interviews with nurse managers and nurses in hospital care. Scand J CaringSci. 2010;24(3):514-22.

14. Wilson $\mathrm{S}$. The middle manager's role in quality improvement. Br J Healthc Manag. 2011;17(10):458-61.

15. Dopson S, Fitzgerald $\mathrm{L}$. The role of the middle manager in the implementation of evidence-based health care. J NursManag. 2006;14(1):43-51.

16. Conway $\mathrm{E}$, Monks K. Change from below: the role of middle managers in mediating paradoxical change. Hum Resour Manag J. 2011;21(2):190-203.

17. Floyd SW, Wooldridge B. Middle management involvement in strategy and its association with strategic type: A research note. Strategic Manage J. 1992:13(S1):153-67.

18. Hyrkäs K, Koivula M, Lehti K, Paunonen-Ilmonen M. Nurse managers' conceptions of quality management as promoted by peer supervision. J Nurs Manag. 2003;11(1):48-58.

19. Birken S, Lee $S$, Weiner B, Chin M, Schaefer C. Improving the effectiveness of health care innovation implementation: middle managers as change agents. Med Care Res Rev. 2013;70(1):29-45.

20. Wilkinson J, Nutley S, Davies H. An exploration of the roles of nurse managers in evidence-based practice implementation. Worldviews EvidBased Nurs. 2011:8(4):236-46.

21. Drach-Zahavy A, Dagan E. From caring to managing and beyond: an examination of the headnurse's role. J AdvNurs. 2002:38(1):19-28.

22. Udod S, Care W. Setting the climate for evidence-based nursing practice: what is the leader's role? Nurs Leadership. 2004:30(39):16.

23. Langley $M R$, et al. The improvement guide: a practical approach to enhancing organizational performance, 2nd Edition.San Francisco: John Wiley \& Sons; 2009.

24. Straus, Sharon E, Holroyd-Leduc J. Knowledge-to-action cycle. Evid Based Med. 2008;13(4):98-100. 